\title{
Unfolding the relationship between seasonal forecast skill and value in hydropower production: A global analysis
}

\author{
Donghoon Lee ${ }^{1,2}$, Jia Yi Ng${ }^{3}$, Stefano Galelli ${ }^{3}$, and Paul Block ${ }^{1}$ \\ ${ }^{1}$ Department of Civil and Environmental Engineering, University of Wisconsin-Madison, Madison, Wisconsin, USA. \\ ${ }^{2}$ Climate Hazards Center, Department of Geography, University of California, Santa Barbara, California, USA. \\ ${ }^{3}$ Pillar of Engineering Systems and Design, Singapore University of Technology and Design, Singapore.
}

Correspondence: Stefano Galelli (stefano_galelli@sutd.edu.sg)

\begin{abstract}
The potential benefits of seasonal streamflow forecasts for the hydropower sector have been evaluated for several basins across the world, but with contrasting conclusions on the expected benefits. This raises the prospect of a complex relationship between reservoir characteristics, forecast skill and value. Here, we unfold the nature of this relationship by studying time series of simulated power production for 735 headwater dams worldwide. The time series are generated by

5 running a detailed dam model over the period 1958-2000 with three operating schemes: basic control rules, perfect forecastinformed, and realistic forecast-informed. The realistic forecasts are issued by tailored statistical prediction models-based on lagged global and local hydro-climatic variables-predicting seasonal monthly dam inflows. As expected, results show that most dams (94\%) could benefit from perfect forecasts. Yet, the benefits for each dam vary greatly and are primarily controlled by the time-to-fill and the ratio between reservoir depth and hydraulic head. When realistic forecasts are adopted, $25 \%$ of dams demonstrate improvements with respect to basic control rules. In this case, the likelihood of observing improvements is controlled not only by design specifications but also by forecast skill. We conclude our analysis by identifying two groups of dams of particular interest: dams that fall in regions expressing strong forecast accuracy and have the potential to reap benefits from forecast-informed operations, and dams with strong potential to benefit from forecast-informed operations but fall in regions lacking forecast accuracy. Overall, these results represent a first qualitative step towards informing site-specific
\end{abstract} hydropower studies.

\section{Introduction}

Hydropower is the leading form of renewable power, contributing to $16 \%$ of global electricity production and $62 \%$ of all renewable electricity generation (IHA, 2019). Total hydropower production is expected to double by 2050, with substantial growth in Asia, Africa, and South America (Zarfl et al., 2015; Zhang et al., 2018). The sustainable operation of hydropower facilities, however, is challenged by hydro-climatic variability, namely seasonal and inter-annual fluctuations in streamflow-and hydropower output-driven by large-scale climate drivers. Examples include the North Atlantic Oscillation (NAO), affecting hydropower in Europe (De Felice et al., 2018), or the El Niño Southern Oscillation (ENSO), affecting one third of the world's hydropower dams ( $\mathrm{Ng}$ et al., 2017). An attractive management option to limit these fluctuations is the use of adaptive reservoir operating policies based on seasonal streamflow forecasts (Troin et al., 2021). Hydropower operators in snowmelt-dominated 
regions, for instance, can rely on seasonal forecasts to commit to reservoir drawdown in early winter in preparation for future inflows. Yet, the benefits reaped from such decision (forecast value) may vary in response to the forecast accuracy, or skill, as well as the design specifications of the reservoir system at hand.

Perhaps unexpectedly, several studies have shown that using streamflow forecasts can lead to tangible gains (Kim and Palmer, 1997; Block, 2011; Libisch-Lehner et al., 2019; Ahmad and Hossain, 2019), but also that these gains vary widely. Maurer and Lettenmaier (2004), for instance, observed a modest 1.8\% increase in hydropower production when re-operating the reservoirs along the Missouri River with perfect forecasts. Similarly, Rheinheimer et al. (2016) found a 1.2\% increase in the economic gain for the Sierra Nevada's hydropower system. In contrast, Hamlet et al. (2002) estimated that seasonal streamflow forecasts could raise hydropower revenue by $\$ 153$ million/year $(>40 \%)$ in the Columbia River basin. How do we explain such differences? To answer this question, we need to understand the relationship between forecast skill, value, and reservoir characteristics. There are two common approaches for tackling this problem. In the analytical approach, one typically uses synthetic forecasts and a hypothetical reservoir system to analytically derive a relationship between the aforementioned variables. For example, You and Cai (2008) derived a theoretical relationship linking the ideal forecast horizon to various factors, such as water stress level, reservoir size, or inflow uncertainty. In a follow-up study, Zhao et al. (2012) investigated the relationship between forecast horizon and uncertainty, identifying an effective forecast horizon that balances the effects of horizon and uncertainty, providing the largest benefit to the reservoir operators. On the other hand, the experimental approach simulates the operations of existing reservoirs systems with seasonal streamflow forecasts to determine their potential value, and, where possible, to build an empirical relationship linking forecast value, skill, and reservoir characteristics. Maurer and Lettenmaier (2004), for instance, attributed the relatively low gains found for the Missouri River basin to the system's large storage capacity (relative to annual inflow). When studying the Sierra Nevada's hydropower system, Rheinheimer et al. (2016) found that forecast value is insensitive to storage capacity, yet highly sensitive to powerhouse capacity.

One limitation of the existing literature is that it illustrates the potential benefits of seasonal forecasts on individual hydropower dams or specific river basins. In turn, this leads to a fragmented knowledge of how forecast skill and reservoir characteristics translate into forecast value. A global-scale assessment of forecast skill and value can fill this gap and provide numerous benefits. First, evaluating forecast skill and value for hundreds of hydropower sites can frame the current body of knowledge within a larger scope, and elicit the wide range of possible benefits observed at individual dams. Second, a global study offers a broad spectrum of actual reservoir characteristics, allowing for an in-depth analysis of how forecast value is modulated by reservoir characteristics. To date, this important aspect has been primarily demonstrated for water supply reservoirs (Anghileri et al., 2016; Turner et al., 2017a), but remains largely unexplored for hydropower dams (Yang et al., 2021). Such added knowledge may not necessarily lead to specific design guidelines, but may still be valuable to operators and planners. For example, a quantitative relationship between reservoir characteristics, forecast skill, and value could be applied in regional analyses designed to determine the minimum forecast skill required by an existing or planned reservoir network (Bertoni et al., 2021). The expected continuous development of forecast systems will only continue to foster such analyses (Johnson et al., 2019; Crochemore et al., 2020; Troin et al., 2021). 
Here, we present a global analysis carried out on 753 headwater dams, representing $10 \%$ of the world's installed hydropower capacity. Specifically, we leverage recent studies demonstrating global streamflow predictability conditioned on large-scale climate variability (Ward et al., 2014; Lee et al., 2018), and develop seasonal inflow forecasts for each dam. Then, we quantify the value of these forecasts by comparing the amount of hydropower simulated by three operating schemes based on realistic forecasts (issued by our model), perfect forecasts, and (no forecasts) control rules. We leverage the wide range of climatic conditions and dam characteristics available in our database to (1) explain how reservoir design properties and forecast skill affect the value of seasonal forecasts, and (2) identify key geographical regions where dams can benefit most from forecasts. The relationships between forecast skill, value, reservoir characteristics, and geographic location revealed through these analyses represent a first step toward informing site-specific studies.

\section{Data}

\subsection{Hydropower dams data}

70 We use the database introduced by $\mathrm{Ng}$ et al. (2017) containing design specifications for 1,593 hydropower reservoirsrepresenting almost $40 \%$ of the world's installed hydropower capacity. The database provides information on dam height, storage capacity, maximum surface area, long-term average discharge, upstream catchment area, geographic coordinates, installed power capacity, maximum turbine flow, and operating goals (e.g., hydropower supply, flood control). The majority of these data are retrieved from the Global and Dam (GRanD) database (Lehner et al., 2011) and complemented with data from the International Commission on Large Dams (ICOLD, 2011), the Global Lakes and Wetlands Database (Lehner and Döll, 2004), and the Global Energy Observatory (GEO, 2016). We filter out all dams affected by upstream regulation, reducing the number from 1,593 to 753, representing head water-only dams. Filtering is based on the Degree Of Regulation (DOR) for each dam, defined as the ratio between the storage volume of the upstream dam(s) and the natural average discharge volume of a given river segment (Grill et al., 2019). We retain only dams with DOR values equal to 0.

To model the relationship between storage and depth, we use an approach commonly adopted in global studies (Van Beek et al., 2011; Turner et al., 2017b). Specifically, we model the storage-depth relationship with Kaveh's method, which assumes an archetypal reservoir shape (Kaveh et al., 2013). This method estimates the reservoir surface area as a function of volume, maximum surface area, depth, and maximum depth. For the limited number of cases in which maximum depth is not available, we adopt Liebe's method and assume that the reservoir is shaped like an inverted pyramid cut diagonally in half (Liebe et al., 2005). To test the accuracy of these assumptions, we infer the bathymetry of each dam from a high-resolution global hydrography dataset (Yamazaki et al., 2019), and retain for comparison approximately 200 reservoirs with dam height and storage capacity estimates comparable to those reported in the GRanD database (see Text S1). Results, reported in Figure S1, indicate that forecast value is not strongly affected by the approach adopted to model the storage-depth relationship.

For each dam, we obtain a monthly inflow time series from the Water and Global Change (WATCH) $20^{\text {th }}$ century model gridded global runoff dataset (Weedon et al., 2011). The runoff data are generated by the global hydrological model WaterGAP (Alcamo et al., 2003), which estimates the accumulated runoff for each grid $\left(0.5^{\circ} \times 0.5^{\circ}\right.$ resolution) using the DDM30 river 
network (Döll and Lehner, 2002). The model is calibrated with discharge data from the Global Runoff Data Center and has been applied to many global water resources studies (Döll et al., 2009; Haddeland et al., 2014). However, the course spatial resolution may be a source of uncertainty for dams located in small catchments. For this reason, we modify the original WATCH database in three ways. First, we consider only the period 1958-2000, which contains more detailed forcing data (Weedon et al., 2011). Second, we manually adjust the position of 270 dams (of the 753 dams) to properly align with the DDM30 river network, using the HydroSHEDS river network (Lehner et al., 2008) and satellite images. Finally, we correct the discharge data to account for any disparity between the upstream catchment area defined by the DDM30 river network and the documented upstream catchment area of each dam ( $\mathrm{Ng}$ et al., 2017).

Climate-specific information for each dam location is also obtained, based on the updated Köppen-Geiger climate classification, which is conditioned on global, long-term monthly precipitation and temperature time series (Peel et al., 2007). Specifically, we use the Köppen-Geiger climate classification that occurs most frequently in the grids upstream of each dam.

\subsection{Hydro-climatological data}

The seasonal forecasts developed here depend on seven potential predictors: four large-scale climate drivers (ENSO, NAO, Pacific Decadal Oscillation (PDO), and the Atlantic Multidecadal Oscillation (AMO)), and three variables accounting for local processes (lagged inflow, snowfall, and soil moisture). The four large-scale climate drivers are interannual, decadal, or multidecadal quasi-periodic oscillations derived from oceanic and atmospheric fields, and play a key role in determining hydroclimate patterns across the world (Lee et al., 2018). To characterize ENSO, we use the Niño 3.4 index, defined as the anomalies of 3-month running mean Sea Surface Temperatures (SST) in the Niño 3.4 region (https://www.esrl.noaa.gov/psd/gcos_wgsp/ Timeseries/Nino34/). The monthly PDO index is defined as the leading principal component of monthly SST anomalies in the North Pacific basin (Zhang et al., 1997). It is obtained from the Joint Institute for the Study of the Atmosphere and Ocean (http://research.jisao.washington.edu/pdo/). For NAO, we use the station-based seasonal NAO index, which is the difference in normalized sea level pressure between Lisbon and Reykjavik (Hurrell and Deser, 2010) (https://climatedataguide.ucar.edu/ climate-data/hurrell-north-atlantic-oscillation-nao-index-station-based). Finally, the AMO index is defined as area-weighted average SST over the North Atlantic basin (Enfield et al., 2001). We use the monthly de-trended and un-smoothed AMO index derived from the Kaplan SST dataset (https://www.esrl.noaa.gov/psd/gcos_wgsp/Timeseries/AMO). For the PDO and AMO indices, we calculate 3-month running means to maintain seasonal persistence.

Monthly soil moisture and snowfall data are obtained from the ERA-40 reanalysis, developed by the European Centre for Medium-Range Weather Forecasts (https://apps.ecmwf.int/datasets/) and WATCH forcing data, respectively. For soil moisture, we aggregate all four volumetric soil water layers of ERA-40. To properly account for the basin-scale soil moisture and snowfall states (Maurer and Lettenmaier, 2004), we calculate the area-weighted average soil moisture and snowfall of all upstream grids for each dam using the DDM30 river network. 


\section{Methods}

The goal of this study is to (1) quantify the value of seasonal inflow forecasts for a global database of hydropower dams, (2) illustrate how reservoir design properties and forecast skill affect the value of seasonal forecasts, and (3) identify regions that could benefit from application of seasonal forecasts. To achieve these goals, we first develop an inflow prediction model for each of the 753 dams (Section 3.1). Then, we simulate hydropower production for each dam under three operating schemes that are based on perfect forecasts, realistic forecasts (issued by our inflow prediction model), and (no forecast) control rules (Section 3.2). Finally, we evaluate the performance of each operating scheme and identify the reservoir design specifications that influence each system's performance (Section 3.3).

\subsection{Dam inflow prediction model}

Two broad alternative approaches for seasonal streamflow forecast development include physically-based models, such as GloFAS (a global-scale forecasting system; Emerton et al. (2018); Harrigan et al. (2020)), or statistical prediction models that leverage the relationship between large-scale climate drivers and local hydro-meteorological processes (Block, 2011; Gelati et al., 2014; Giuliani et al., 2019). Here, we select the second approach for two reasons. First, re-forecasts issued by globalscale forecasting systems are only available for a relatively-short hindcast period (typically two decades; Harrigan et al. (2020)), whereas the time series of globally-available hydro-climatological data are significantly longer. Second, the prediction horizon of most physically-based approaches (a few days to 3-4 months) falls short of our preferred lead times up to seven months, so as to test the potential of realistic forecasts for a broad spectrum of reservoirs-including those characterized by slow storage dynamics.

Our long-range inflow prediction models uses Principal Component Regression (PCR) and includes four lagged large-scale climate drivers and prior streamflow conditions to predict streamflow at 1,200 stations, following Lee et al. (2018). This approach is readily implemented globally and has demonstrated fair (realistic) predictive skill (Lee et al., 2018). While Lee et al. (2018) predict seasonal (3-month) streamflow averages, here we develop independent monthly prediction (MP) models for the subsequent seven calendar months. For example, forecasts issues at the end of February include monthly inflows from March (MP1) to September (MP7).

The methodology relies on the following steps, illustrated in Figure 1. First, we normalize (log-normalize for streamflow) and detrend all predictors and streamflow observations to avoid spurious correlation. Then, we estimate the lag-correlations between monthly inflows over the next 7 months and climate indices (1-8 months ahead), snowfall (current to 8 months ahead), inflow and soil moisture (current month). Only statistically significant predictors are subsequently used to develop the MP models. If only a single (statistically significant) predictor exists, we apply a linear regression (LR) model; otherwise, we apply the PCR model to avoid possible multi-collinearities. In the PCR process, we truncate only the last principal component, which is typically associated with multi-collinearities, as suggested by Jolliffe (2002) and Wilks (2011). To select the optimal leadtimes of the lagged predictors, we apply a leave-one-out cross-validation (LOOCV) scheme. Specifically, all combinations of lead-months for the lagged predictors are cross-validated; then, the optimal set of lead-months is determined based on 
the minimum mean squared error (MSE). The models are developed with $70 \%$ of the available data (corresponding to the period 1958-1987) and validated with the remaining data (1988-2000), so as to measure the model's independent performance over the recent period. In the validation process, we evaluate the model performance using two skill scores, namely the mean squared error skill score (MSESS) and the Gerrity skill score (GSS) (Text S2 and Figure S2). If an MP model has no statistically significant predictors, or either an MSESS or GSS value less than 0, the long-term average for that month (i.e. climatological mean) is applied instead. The overall accuracy of the reservoir inflow predictions is assessed with the Kling-Gupta efficiency ( $K G E$ ), which compares correlation, bias, and variability of the predicted and observed discharge (Gupta et al., 2009). The $\mathrm{KGE}$ is defined as:

$K G E=1-\sqrt{(r-1)^{2}+(\beta-1)^{2}+(\gamma-1)^{2}}$,

where $r$ is the correlation coefficient, $\beta$ the bias ratio of the mean inflow $\left(\mu_{s} / \mu_{o}\right), \gamma$ the variability ratio $\left(C V_{s} / C V_{o}\right), \mu$ the mean flow, $C V$ the coefficient of variation, and $s$ and $o$ are two indices indicating simulated (predicted) and observed inflow values, respectively.

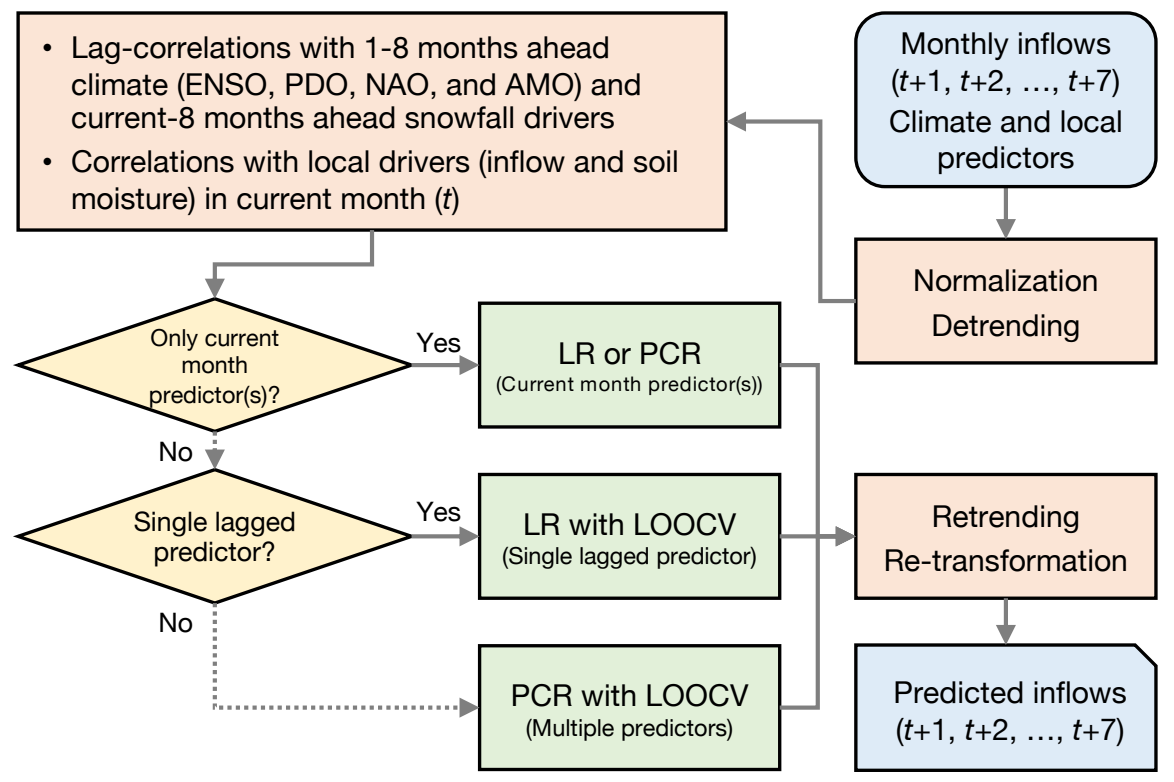

Figure 1. Graphical representation of the monthly prediction (MP) model scheme. At each calendar month $t$, we develop seven independent models to predict monthly inflows for the next seven months: MP1 $(t+1)$, MP2 $(t+2), \ldots$, MP7 $(t+7)$. 


\subsection{Reservoir operation model}

\subsubsection{Reservoir model}

An essential component of the operating scheme is the reservoir mass balance described below:

$S_{t+1}=S_{t}+Q_{t}-E_{t}-R_{t}-S_{p i l l}$

$0 \leq S_{t} \leq S_{\text {cap }}$

$0 \leq R_{t} \leq \min \left(S_{t}+Q_{t}-E_{t}, R_{\max }\right)$

where $S_{t}$ is the reservoir storage at month $t, Q_{t}$ the inflow volume (retrieved from the WaterGAP model, as described in Section

2.1), $E_{t}$ the evaporation loss, and $R_{t}$ the water released through the turbines. Both $S_{t}$ and $R_{t}$ are constrained by the reservoir design specifications. Specifically, the storage cannot exceed the reservoir capacity $S_{c a p}$ (eq. (2b)), while the discharge is bounded by the water availability and capacity $R_{\max }$ of the turbines (eq. (2c)). Excess water, if any, is spilled:

$\operatorname{Spill}_{t}=\max \left(0, S_{t}+Q_{t}-R_{t}-E_{t}-S_{c a p}\right)$.

The hydropower production $P_{t}$ (in MW) is calculated as follows:

$P_{t}=\eta \cdot \rho \cdot g \cdot r_{t} \cdot h_{t}$

where $\eta$ is the efficiency of the turbines (assumed constant at 0.9 over the simulation period), $\rho$ the water density $\left(1,000 \mathrm{~kg} / \mathrm{m}^{3}\right)$, $g$ the gravitational acceleration $\left(\mathrm{m} / \mathrm{s}^{2}\right), r_{t}$ the average release rate $\left(\mathrm{m}^{3} / \mathrm{s}\right)$ implied by the monthly release volume $R_{t}$, and $h_{t}$ the hydraulic head (m). The latter is taken as the average head between time $t$ and $t+1$.

\subsubsection{Benchmark scheme: control rules}

Our benchmark operating scheme relies on the approach proposed by $\mathrm{Ng}$ et al. (2017), in which the behaviour of the hydropower operators is modelled as an optimal control problem. This approach builds on two main assumptions. First, the goal of the operators is to maximize hydropower production over the long term. This objective provides a tangible indication of hydropower performance, so it is commonly adopted in large-scale studies (e.g., Van Vliet et al. (2016)). Second, the release decision $R_{t}$ depends on the reservoir storage $S_{t}$, the previous period's inflow volume $Q_{t-1}$, and month of year $t$ - a common 
choice in real-world reservoir operating schemes (Hejazi et al., 2008). In other words, the approach assumes that each reservoir is operated through a unique periodic look-up table of turbine release decisions, which is generated through stochastic dynamic programming (Loucks et al., 2005; Soncini-Sessa et al., 2007). In the optimization, the inflow process is modelled with a first order, periodic Markov chain, whose parameterization is derived from the inflow data. This means that climatology and interannual inflow variability are embedded in this operating scheme. Such schemes are more sophisticated than operating schemes relying only on storage level and time of the year (Denaro et al., 2017; Giuliani et al., 2019; Ahmad and Hossain, 2020) and are more consistent with inferred operating rules (Turner et al., 2020). A detailed validation of the operating rules-based on values of observed hydropower production in 107 countries during the period 1980-2000 - is reported in Turner et al. (2017b). The time series of all process variables (e.g., inflow, storage, release, hydropower production) obtained by the benchmark control scheme are available on HydroShare (http://www.hydroshare.org/resource/ca365ffb1a1f49df8b77e393be965fd8).

\subsubsection{Forecast-informed scheme}

To assess the value of seasonal streamflow forecasts, we adopt an adaptive scheme based on the receding horizon principle (Bertsekas, 1976). At month $t$, we use a deterministic 7-month streamflow forecast to determine the value of the release decisions for the next seven months, and then implement only the decision $R_{t}$ for the first month. At month $t+1$, when a new 7-month forecast becomes available, a new sequence of release decisions is determined. Each decision-making process is formulated through an optimization problem that maximizes the hydropower production over the forecast horizon while accounting for the benefits associated with the resulting storage at the end of the forecast horizon:

$\min _{R_{t}, R_{t+1}, \ldots, R_{t+6}} \sum_{i=0}^{6} P_{t+i}+X\left(S_{t+7}\right)$,

where $P_{t}$ is the hydropower production (see eq. (3)) and $X(\cdot)$ a function accounting for the long-term effect of the release decisions. Specifically, the function penalizes decisions that solely optimize energy production in the short term, risking water availability depletion in the long term. Following a common practice in forecast-informed schemes (Soncini-Sessa et al., 2007), we set $X(\cdot)$ equal to the benefit function obtained by the benchmark control rules, which contains information about the expected long-term hydropower production for a given storage level. Thus, the real-time information provided by the forecasts may alter decisions otherwise based solely on the benchmark scheme. As our inflow forecast model gives a deterministic 7month forecast, the optimization problem is solved at each time step using deterministic dynamic programming (Turner et al., 215 2017a).

The scheme is implemented using both 'perfect' and realistic forecasts. Both benchmark and forecast-informed schemes are simulated over the period 1958-2000. During the simulation, all release decisions are constrained to satisfy downstream environmental flow requirements, calculated using the variable monthly flow method (Pastor et al., 2014). All experiments are carried out with the R package reservoir (Turner and Galelli, 2016). 


\subsubsection{Considering additional operating objectives and finer temporal scales}

Of the 735 headwater dams in the database, 174 dams are also operated for flood control purposes. For these dams, we penalize spill to account for flood control and formulate the optimization objective as follows (in both benchmark and forecast-informed schemes):

$\min _{R_{t}, R_{t+1}, \ldots, R_{t+6}} \sum_{i=0}^{6}\left(w_{1} \cdot \frac{S_{p i l l}+i}{p_{95}(Q)}+w_{2} \cdot\left(1-\frac{P_{t+i}}{P}\right)\right)+X\left(S_{t+7}\right)$,

where $w_{1}$ and $w_{2}$ are the weights associated with the flood control and hydropower objectives (set to 0.5 here), $p_{95}(Q)$ the $95^{\text {th }}$ percentile of the inflow time series $Q$, and $P$ the dam installed hydropower capacity (in MW). Clearly, additional objectives may infleunce hydraulic head or the release trajectory, thereby affecting hydropower production (Zeng et al., 2017).

A second modification of the reservoir operation model concerns the monthly decision-making time step, which may not be suitable for reservoirs with small storage capacity relative to inflow (time-to-fill). We therefore identify a group of 94 reservoirs for which the time-to-fill is shorter than two months, and adopt for this group only a weekly time step. Since the inflow forecasts have a monthly resolution, we disaggregate each forecast into four values using the $k$-nearest neighbors algorithm (Nowak et al., 2010). Further details are reported in Text S3.

\subsection{Reservoir performance evaluation}

It is reasonable to hypothesize that that the value of seasonal streamflow forecasts—-here measured in terms of hydropower production - depends not only on predictive skill, but also on reservoir characteristics. For example, a reservoir constrained by small turbine capacity may perform adequately utilizing control rules alone, as storage is sufficient to buffer inflow variability. We are thus interested in quantifying forecast value as well as understanding how value varies as a function of both skill and reservoir characteristics. This leads us to the following performance metrics.

\subsubsection{Impact of design characteristics on perfect forecast-based operations}

Initially excluding the effect of actual forecast skill, the following performance metric represents the expected improvement from perfect forecast-informed operations as compared to control rules-based operations:

$I_{P F}=\frac{H_{P F}-H_{c t r l}}{H_{P F}} \times 100 \%$,

where $H_{P F}$ and $H_{c t r l}$ represent the total hydropower production (for the period 1958-2000) obtained with perfect forecastinformed operations and control rules, respectively. A value equal to zero indicates that the control rules are comparable to the (perfect) forecast-informed operations, whereas a positive value suggests that forecast-informed operations could be beneficial. Even though some dams are operated with an additional flood control objective, we use the same measure for all dams so as to ensure a consistent comparison of forecast value. 
To understand how reservoir characteristics may influence benefits attained with perfect forecasts, we proceed in two steps. First, we label each dam as success or failure depending on whether the associated value of $I_{P F}$ is larger or smaller than the mean value of $I_{P F}$ across all dams. (As this labelling is rather arbitrary, we later assess the sensitivity of our analysis to changes in the threshold.) Note that failure implies that the control rules and perfect forecast-informed operations generate a similar amount of hydropower, meaning that information on storage and previous-month inflow are sufficient for near-optimal release decisions. Second, we explain the likelihood of achieving success through a logistic regression model in which the probability of the binary response variable taking a particular value is a function of the predictor variables. We consider two predictors, namely (1) the ratio of reservoir storage capacity to the mean monthly inflow $\left(x_{f i l l}\right.$, measured in months), and (2) the ratio of maximum reservoir depth to maximum hydraulic head $\left(x_{\text {depth }}\right)$. The second predictor varies between 0 and 1 , and indicates the extent to which hydraulic head is dependent on the depth of the reservoir. The logistic regression model is crossvalidated with a 10-fold cross-validation scheme, and evaluated using two metrics, accuracy and Cohen's kappa (McHugh, 2012). Accuracy is the ratio of correctly predicted observations (true positives and true negatives) to the total number of observations. Cohen's kappa is an adjusted accuracy score that accounts for the possibility of correct predictions occurring by chance. The modelling exercise is carried out with the R package caret. For additional details, please refer to Text $\mathrm{S} 4$, and Table S1-S3 in the Supplement.

\subsubsection{Impact of forecast skill and design characteristics on realistic forecast-based operations}

Integrating realistic forecasts in lieu of perfect forecast information, we introduce the following performance metric:

$I_{D F}=\frac{H_{D F}-H_{c t r l}}{H_{P F}} \times 100 \%$

where $H_{D F}$ represents the total hydropower production (for the period 1958-2000) obtained using realistic forecast-informed operations. $I_{D F}$ is then combined with $I_{P F}$ to calculate the performance metric $I$ that quantifies the potential improvement between realistic and perfect forecast-informed operations:

$I=\frac{H_{D F}-H_{c t r l}}{H_{P F}-H_{c t r l}}=\frac{I_{D F}}{I_{P F}}$.

A value of $I$ equal to 1 indicates that benefits from the actual forecasts equal those utilizing perfect forecasts. A value of 0 denotes performance equivalent to applying the control rules only, while a negative value implies that the forecast-informed scheme is inferior to the control rules. We calculate this metric only for the subset of dams achieving a value of $I_{P F}$ greater than the mean value of $I_{P F}$ to better understand if the benefits modeled with perfect forecasts may be attainable with realistic forecasts.

To explain how the metric $I$ varies, we use a linear regression model accounting for both forecast skill and reservoir characteristics. The predictor characterizing the forecast skill is $x_{M d A P E}$, the median absolute percentage error of the forecast, used in place of $K G E$ because it shows a higher correlation with $I$. (While $K G E$ gives a broad view of the forecast skill by 
comparing correlation, mean, and standard deviation of the predicted and observed inflows, $M d A P E$ accounts for the forecast error at every time step of the inflow time series. This may make $M d A P E$ a more suitable predictor, as the error at each time step affects the release decisions and, ultimately, hydropower production.) The second predictor is $x_{\text {exceed }}$, the fraction of time that inflow exceeds the maximum turbine release rate. For more details on the choice of predictors, please refer to Text S5 and Table S3-S4.

\section{Results}

In this section, we first present the accuracy of the inflow prediction models (Section 4.1) and performance of the forecastinformed schemes (Section 4.2). Then, we quantify the extent to which reservoir design characteristics and forecast skill affect the value of seasonal forecasts (Section 4.3). Lastly, we classify all dams according to their potential to benefit from forecasts, and identify key geographical regions that may benefit the most from forecasts (Section 4.4).

\subsection{Potential predictors and accuracy}

As shown in Figure 2, reservoir inflow exhibits significant correlation with climate and local drivers (potential predictors).

Yet, this relationship changes across the annual cycle. Evaluating months when a higher percentage of dams is significantly correlated with predictors, some well-known climatic teleconnections can be observed-e.g., ENSO and winter-spring streamflow in North America and Europe, NAO and spring-summer peak flows in the northern extratropic regions, and PDO and summer streamflow in southeastern North America and central South America (Figure S3). On average, 27\%, 37\%, 28\%, 20\%, and $36 \%$ of the reservoir catchments are significantly correlated with ENSO, NAO, PDO, AMO, and snowfall, respectively. Additionally, and not surprisingly, inflow for most dams (72\%) exhibits significant 1-month lead autocorrelation. An exception is represented by some dams during the period March-April, especially in areas with minimal baseflow (Figures 2 and S3). Soil moisture at a 1-month lead is statistically significantly correlated with inflow at $47 \%$ of dams across all months with a seasonality similar to inflow.

Reservoir inflow and climatic predictors are often (significantly) correlated across several lead months. In these cases, climate predictors are very likely to be included in multiple MP models for various leads, although the correlation may decrease with longer lead-time. When a climate predictor is significantly correlated with reservoir inflow at a 1-month lag (MP1), 74\% and $38 \%$ of the time it is also included at the 4-month lag (MP4) and 7-month lag (MP7), respectively. Snowfall has a similar retention rate. However, and as expected, autocorrelation in inflow and soil moisture drops more precipitously with longer lead; only 53\% (28\%) of the time, when lagged inflow and soil moisture are included as predictors in MP1, they are also included in MP4 (MP7). Globally, an average of 2.7, 1.7, and 0.9 predictors are included in the MP1, MP4, and MP7 models, respectively. In very few cases, the number of predictors increases with longer lead-time. For months when no potential predictors are identified, or either MSESS or GSS is less than zero, the long-term mean inflow for that month is used.

Across the annual cycle, the average number of months in which at least one predictor is included (and thus a predictive model developed) is equal to 8.3 months (MP1), 6 months (MP4), and 4.2 months (MP7) (see Figure 3). As noted previ- 


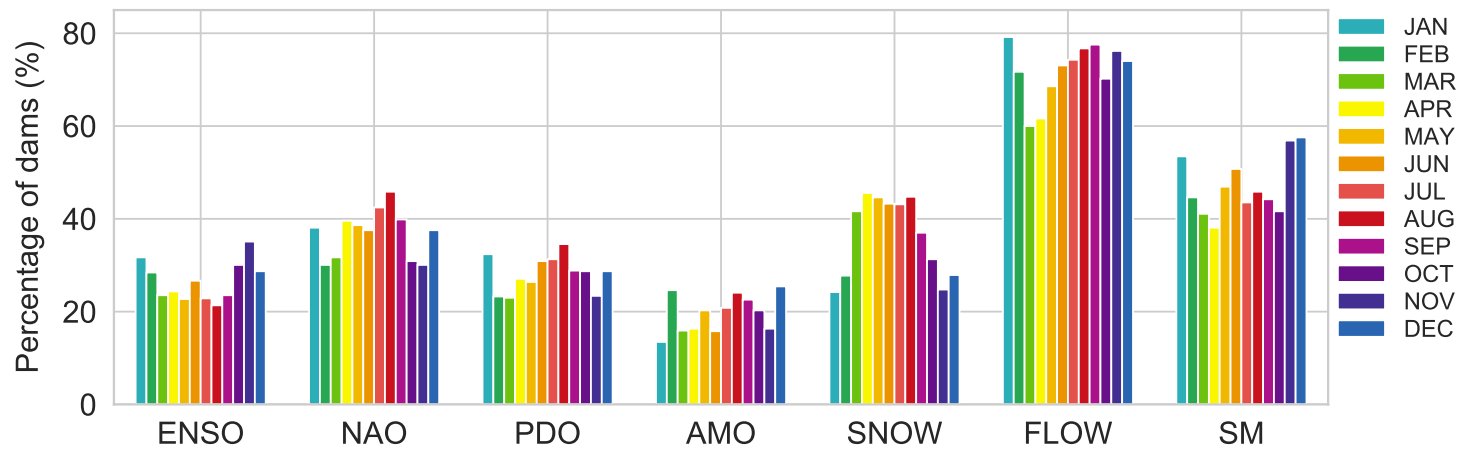

Figure 2. Percentage of dams significantly correlated with lagged predictors (ENSO, NAO, PDO, AMO, and snowfall) and 1-month ahead predictors (inflow and soil moisture) in each calendar month.

ously, a lack of long-lead inflow autocorrelation is predominantly responsible for this drop (and thus for increased reliance on climatology-based forecasts). Prediction accuracy also decreases with lead-time; average $K G E$ values are 0.64 and 0.56 for MP1 and MP7, respectively (Figure 3). Given that prediction accuracy generally declines with lead time, the highest $K G E$ scores across all MP models are associated with MP1 for $68 \%$ of the dams. For the remaining models, the highest prediction accuracy is recorded for 5\% (2\%) of dams in the MP4 (MP7) models, emphasizing that skillful forecasts at longer leads do exist, such as in Europe or northwestern and southeastern U.S. (Figure $3 \mathrm{~b}$ and 3c). As for the geographical distribution of $K G E$, we find relatively high $K G E$ scores in several regions, including North America, eastern South America, Europe, and some regions in western Africa and Asia, where inflows correlate with most of the considered predictors (Figures 3 and S3).

For all MP models, the $K G E$ has an average value of about 0.56 , which is regarded as a fair skill score outcome. While uniquely tailored forecasts could be produced for each dam considering more local influences, the current prediction approach performs well globally and reflects achievable long-range inflow predictions. Considering the superior performance of the MP1 model, the forecast skill of MP1 only is retained to represent the overall forecast skill in the following analyses.

\subsection{Performance of forecast-informed operations}

The expected performance of perfect and realistic forecast-informed operations is notably different across the 735 hydropower dams (Figure 4). With perfect forecast-informed operations (Figure 4a), we observe a substantial increase in hydropower production with respect to the baseline control rules. Specifically, 94\% of dams exhibit a positive value of the performance metric $I_{P F}$; mean improvement is $4.7 \%$ and maximum improvement is $60 \%$. For the small number of dams that do not benefit from perfect forecasts, the value of $I_{P F}$ does not drop below $-1.7 \%$. Small negative values of $I_{P F}$ are likely a result of the discretization needed by dynamic programming to optimize the release sequence (eq. (4)), hence allowing control rules to outperform perfect forecast-informed operations. Considering all dams collectively, an additional 24 TWh per year of hydroelectricity are generated when adopting the perfect forecast-informed approach in lieu of baseline control rules. This is equivalent to $0.57 \%$ of the 4,200 TWh of hydropower globally generated in 2018 (note that the headwater dams used here 


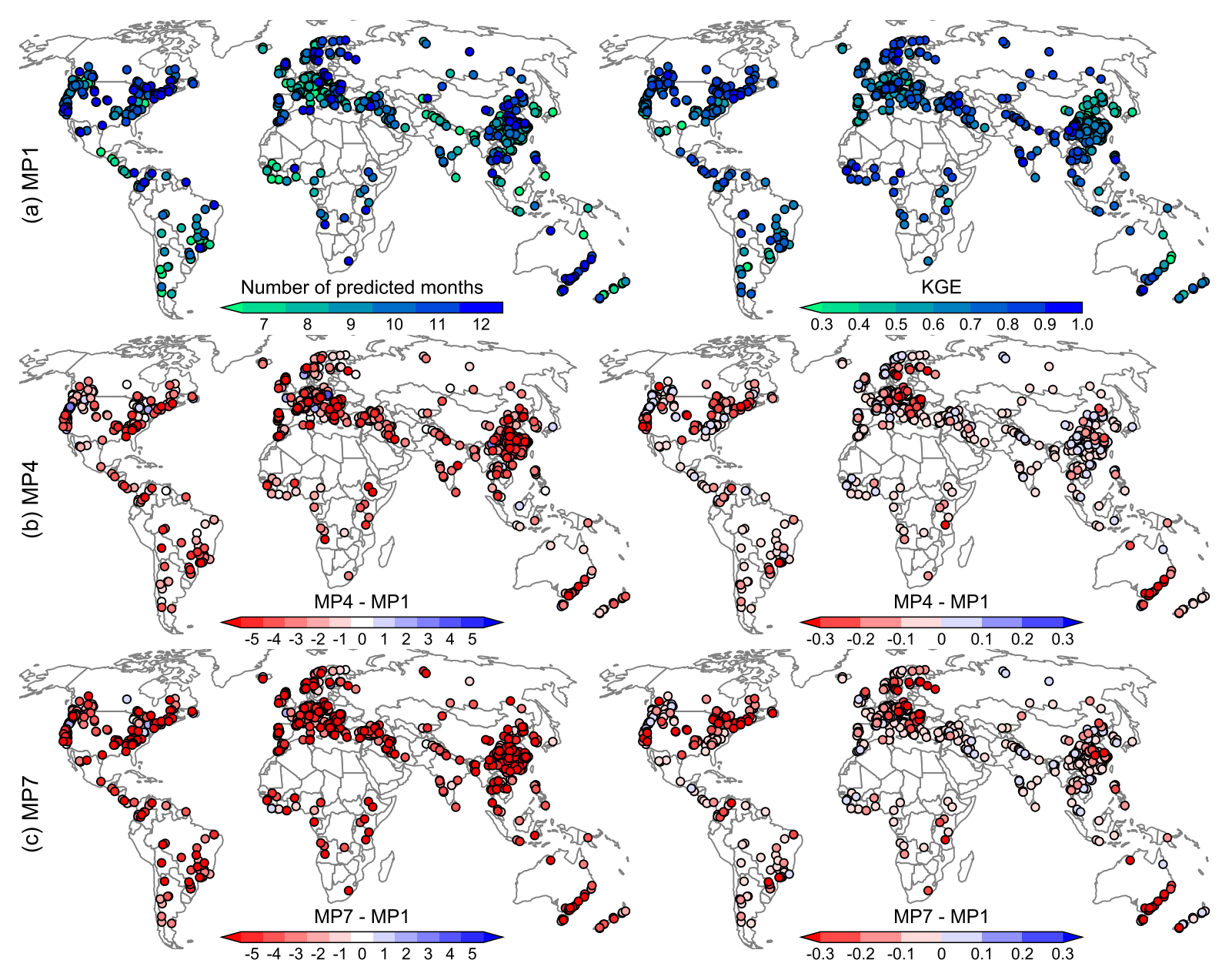

Figure 3. Number of months in which a predictive model is developed (left) and corresponding KGE (right). Taking a model with a lead-time of 1 month (MP1) as reference (a), we report the difference between MP1 and MP4 (b) and MP1 and MP7 (c).

represent $10 \%$ of the world's installed capacity) (IHA, 2019). Such modest global benefit and large range of individual benefits suggest that the forecast value is highly dependent on the reservoir characteristics (see Section 4.3).

When realistic forecast-informed operations are adopted (Figure 4b), a smaller number of dams exhibit increased hydropower production. $I_{D F}$ ranges from $-24 \%$ to $28 \%$, with $25 \%$ of dams showing a positive value of $I_{D F}$. The 184 dams with positive $I_{D F}$ values show an average improvement of $2.3 \%$ and collectively contribute an additional 1.7 TWh per year in hydropower production - $7 \%$ of the $24 \mathrm{TWh}$ of additional hydropower obtainable from perfect forecasts. This decline in performance is expected, as realistic forecasts introduce a non-negligible prediction error. Yet, it should also be noted that less than $20 \%$ of dams have a $K G E$ value below 0.5 , whereas a disproportionately larger number of dams exhibit a negative $I_{D F}$ value. This suggests that for a large number of dams control rule-based operations are superior to realistic forecast-informed 
(a)
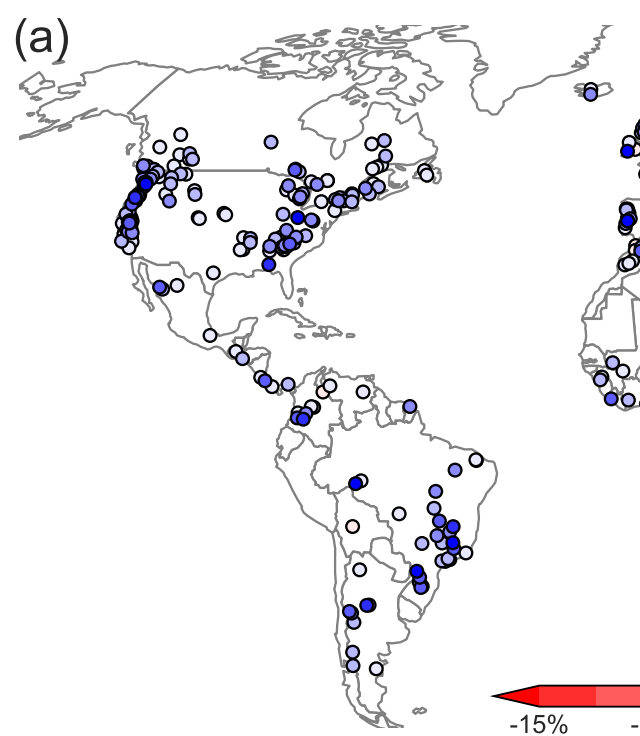

$\infty$
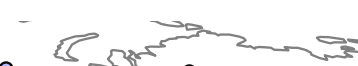

(b)
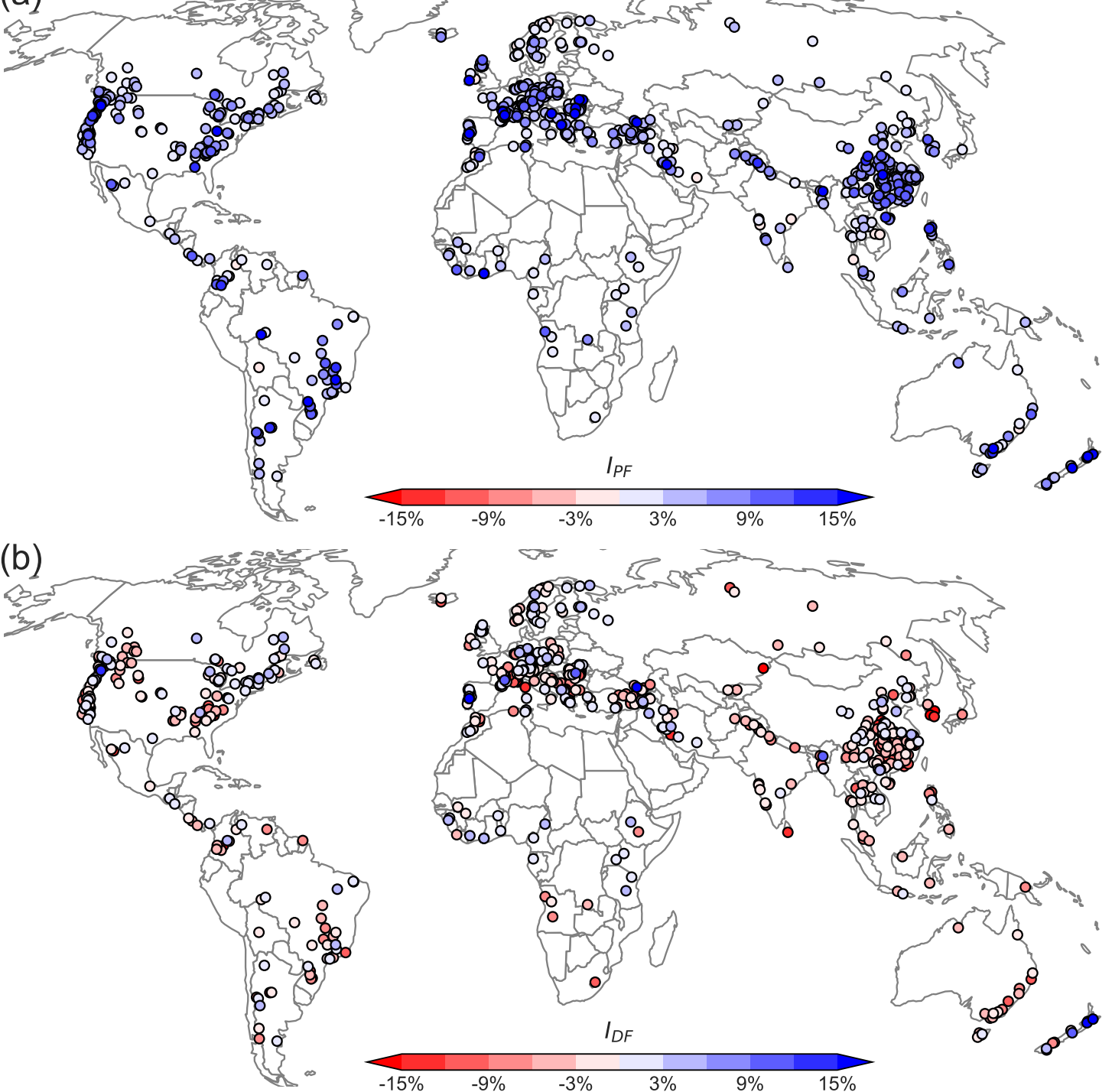

$I_{P F}$
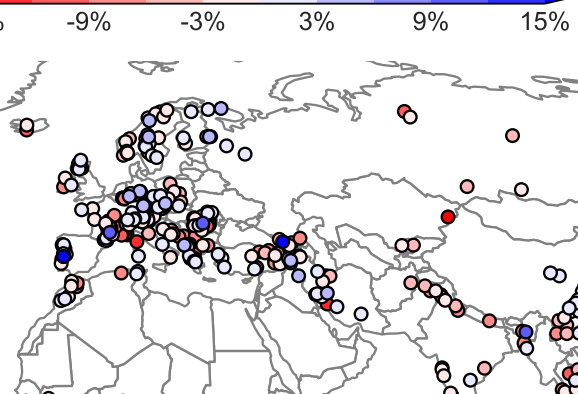


\subsection{Evaluation of prediction accuracy and reservoir characteristics} have a low value of $x_{\text {depth }}$, a high hydraulic head is maintained even when storage is low, thereby minimizing the utility of forecasts. These are systems relying on waterfalls, or hilly terrains, to divert part of the water and gain hydraulic head.

Table 1. Coefficients of logistic regression to predict if $I_{P F}>4.7 \%$. The term 'Estimate' represents the increase in log-odds of a dam attaining success per unit increase in the value of the predictors.

\begin{tabular}{lcccc}
\hline Predictors & Estimate & Std. Error & Z-value & $\operatorname{Pr}(>|z|)$ \\
\hline (Intercept) & -1.16 & 0.25 & -4.62 & $<0.01$ \\
$x_{\text {depth }}$ & 2.84 & 0.31 & 9.25 & $<0.01$ \\
$x_{\text {fill }}$ & -0.10 & 0.01 & -8.76 & $<0.01$ \\
\hline
\end{tabular}

Considering only the subset of 269 dams that have an $I_{P F}$ value larger than $4.7 \%$, we apply a linear regression model to estimate the performance metric $I$. This time, the predictors include $x_{M d A P E}$ (median absolute percentage error of forecast inflows) and $x_{\text {exceed }}$ (the fraction of time that inflow exceeds the maximum turbine release rate). The linear regression model has an adjusted $R^{2}$ of 0.31 , which can be increased further by considering other variables related to inflow variability and hydraulic head. The reader is referred to Table S4-5 for more complex models that include additional predictors.

The results are presented in Table 2 and illustrated in Figure 6. As expected, higher forecast skill (lower $x_{M d A P E}$ ) increases the potential benefits realized by the realistic forecasts; a $1 \%$ decrease in $x_{M d A P E}$ increases $I$ by 0.03 . Reservoir characteristics can play an important role, as certain configurations allow dams and hydropower production to benefit from realistic forecasts. 
https://doi.org/10.5194/hess-2021-518

Preprint. Discussion started: 30 November 2021

(c) Author(s) 2021. CC BY 4.0 License.
Hydrology and

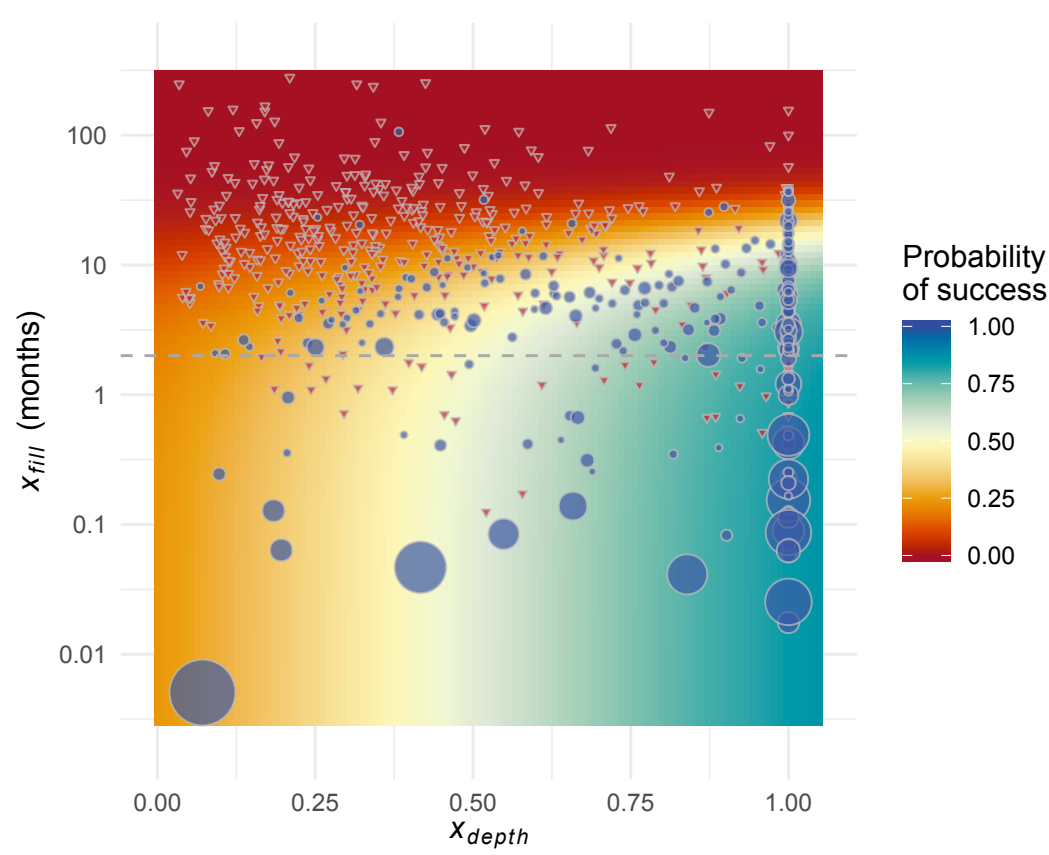

Figure 5. Probability of success estimated using a logistic regression model with predictors $x_{\text {depth }}$ and $x_{f i l l}$ (in log scale). Red corresponds to a probability of success equal to zero, meaning that the dam is likely to do well with the control rules. Blue represents a probability of success equal to 1, meaning that a dam is likely to benefit from forecast-informed operations. Each point in the plot represents one of the 735 dams. Blue circles represent dams labelled as success $\left(I_{P F}>4.7 \%\right)$ and red triangles represents failures. The size of the blue circles represents the value of $I_{P F}$. All red triangles have the same size. Dams below the dashed line $\left(x_{f i l l}=2\right)$ are operated with a weekly time step. Dams with low values of $x_{\text {fill }}$ (small storage capacity relative to inflow rate) and high $x_{\text {depth }}$ (lacking a natural waterfall) are more likely to benefit from forecast-informed operations.

Specifically, we find that dams in which inflow frequently exceeds maximum turbine release (large values of $x_{\text {exceed }}$ ) are more likely to benefit from forecast-informed operations - even when forecasts are not very accurate, as shown by the diagonal divide in Figure 6. This is predominantly a result of both forecast and observed inflow frequently exceeding the maximum turbine release rate, a situation in which the release decision would be the same regardless, so consequently inaccurate forecasts do not penalize hydropower production.

Table 2. Coefficients of linear regression to predict $I$.

\begin{tabular}{lcccc}
\hline Predictors & Estimate & Std. Error & Z-value & $\operatorname{Pr}(>|z|)$ \\
\hline (Intercept) & -0.18 & 0.12 & -1.485 & 0.139 \\
$x_{M d A P E}$ & -0.03 & 0.004 & -8.554 & $<0.01$ \\
$x_{\text {exceed }}$ & 2.36 & 0.30 & 7.752 & $<0.01$ \\
\hline
\end{tabular}


https://doi.org/10.5194/hess-2021-518

Preprint. Discussion started: 30 November 2021

(C) Author(s) 2021. CC BY 4.0 License.
Hydrology and

Earth System Sciences

Discussions

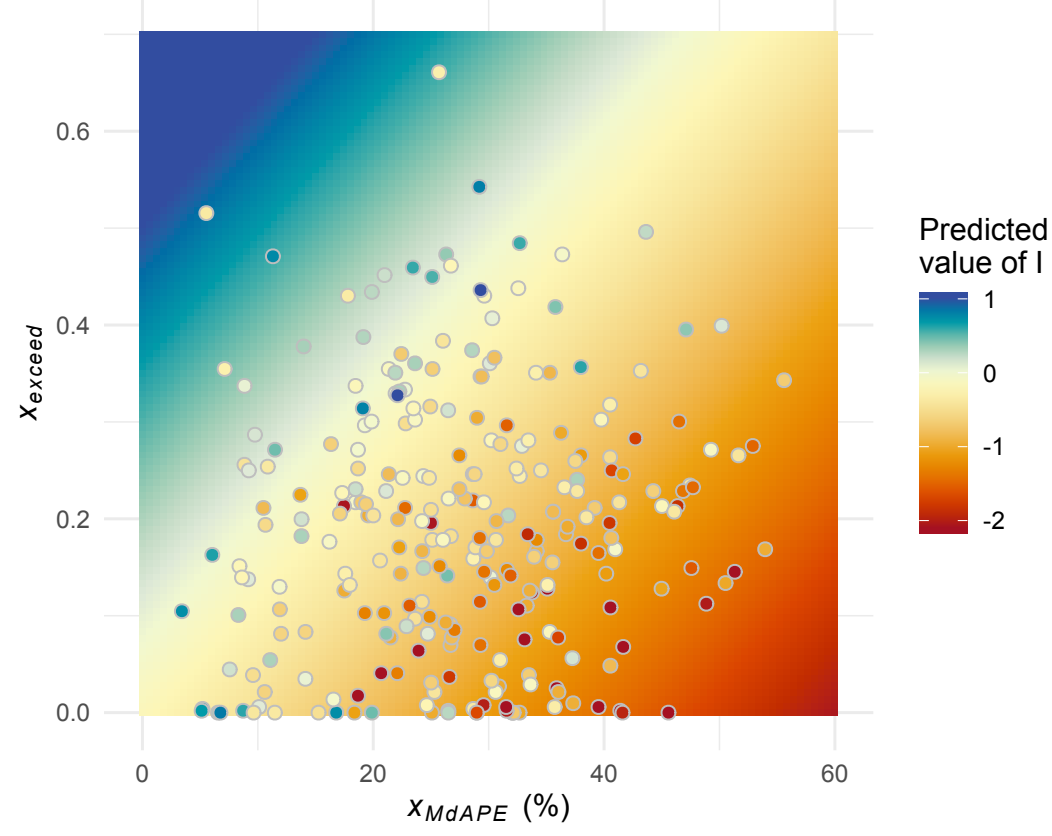

Figure 6. Potential benefits realized by realistic forecast $(I)$ predicted using linear regression with predictors $x_{\text {exceed }}$ and the median absolute percentage error $\left(x_{M d A P E}\right)$. Red corresponds to negative values of $I$, meaning that the performance of realistic forecasts is worse that the one attained by control rules. Blue corresponds to positive values of $I$, meaning that realistic forecasts outperform control rules. Each point corresponds to one of the 269 dams with $I_{P F}>4.7 \%$. The corresponding color represents the value of $I$ attained via simulation with the reservoir operation model. Dams with accurate forecasts and high values of $x_{\text {exceed }}$ (inflow frequently exceeds maximum turbine release) tend to have greater hydropower benefits realized from realistic forecasts.

\subsection{A classification of hydropower dams}

Building on the results described above, we divide the dams into four groups on the basis of their potential to benefit from perfect forecast-informed operations (high potential if $I_{P F}>4.7 \%$ and low potential otherwise) and forecast skill (good forecast if $x_{M d A P E}<20 \%$ and poor forecast otherwise). The cut-off value for $I_{P F}$ is inferred from the previous analysis (logistic regression model), while the cut-off for $x_{M d A P E}$ divides the 735 dams into two groups of one third (good forecast) and two thirds (poor forecast) of the observations. The distribution of the dams across the four groups (and Köppen-Geiger climate zones) is reported in Table 3. Two groups of dams of particular interest include (1) dams that fall in regions expressing strong forecast accuracy and have the potential to reap benefits from forecast-informed operations (9\% of the total number of reservoirs), and (2) dams with strong potential to benefit from forecast-informed operations but lack forecast accuracy (28\%). As discussed in Section 5, this lack of forecast accuracy could be readily addressed by adopting more sophisticated forecast models or further leveraging local predictors. 
Table 3. Distribution of dams across climate zones. In columns 2-9, $\mathrm{H}$ and L indicate the potential (high/low) of benefiting of forecasts, while $\mathrm{G}$ and $\mathrm{P}$ indicate the quality (good/poor) of realistic forecast. Columns 2-5 (6-9) are the number (percentages) of dams in each group. The last two columns report the percentages of dams with high potential and good forecast, respectively. Values reported in bold indicate whether the observed frequency is statistically different from the expected frequency (global average in the final row) $\left(p<0.05\right.$ using $\chi^{2}$ test).

\begin{tabular}{|l|cccc|cccc|cc|}
\hline Climate & HG & HP & LG & LP & HG\% & HP\% & LG\% & LP\% & High\% & Good\% \\
\hline Af & 0 & 9 & 3 & 3 & 0.00 & 0.60 & 0.20 & 0.20 & 0.60 & 0.20 \\
Am & 4 & 6 & 5 & 4 & 0.21 & 0.32 & 0.26 & 0.21 & 0.53 & 0.47 \\
Aw & 7 & 6 & 26 & 4 & 0.16 & 0.14 & 0.61 & 0.09 & 0.30 & $\mathbf{0 . 7 7}$ \\
BWh & 2 & 2 & 2 & 0 & 0.33 & 0.33 & 0.33 & 0.00 & 0.67 & 0.67 \\
BWk & 0 & 3 & 1 & 0 & 0.00 & 0.75 & 0.25 & 0.00 & 0.75 & 0.25 \\
BSh & 1 & 2 & 4 & 6 & 0.08 & 0.15 & 0.31 & 0.46 & 0.23 & 0.39 \\
BSk & 0 & 2 & 6 & 5 & 0.00 & 0.15 & 0.46 & 0.39 & 0.15 & 0.46 \\
Csa & 4 & 11 & 9 & 19 & 0.09 & 0.26 & 0.21 & 0.44 & 0.35 & 0.30 \\
Csb & 6 & 15 & 4 & 10 & 0.17 & 0.43 & 0.11 & 0.29 & $\mathbf{0 . 6 0}$ & 0.29 \\
Cwa & 5 & 25 & 8 & 16 & 0.09 & 0.46 & 0.15 & 0.30 & $\mathbf{0 . 5 6}$ & 0.24 \\
Cwb & 1 & 3 & 7 & 2 & 0.08 & 0.23 & 0.54 & 0.15 & 0.31 & 0.62 \\
Cfa & 2 & 56 & 6 & 58 & 0.02 & 0.46 & 0.05 & 0.48 & $\mathbf{0 . 4 8}$ & $\mathbf{0 . 0 7}$ \\
Cfb & 9 & 15 & 9 & 41 & 0.12 & 0.20 & 0.12 & 0.55 & 0.33 & 0.24 \\
Dsa & 0 & 2 & 1 & 2 & 0.00 & 0.40 & 0.20 & 0.40 & 0.40 & 0.20 \\
Dsb & 2 & 3 & 5 & 4 & 0.14 & 0.21 & 0.36 & 0.29 & 0.36 & 0.50 \\
Dsc & 0 & 1 & 1 & 1 & 0.00 & 0.33 & 0.33 & 0.33 & 0.33 & 0.33 \\
Dwa & 0 & 5 & 1 & 8 & 0.00 & 0.36 & 0.07 & 0.57 & 0.36 & 0.07 \\
Dwb & 1 & 1 & 2 & 1 & 0.20 & 0.20 & 0.40 & 0.20 & 0.40 & 0.60 \\
Dwc & 2 & 1 & 2 & 0 & 0.40 & 0.20 & 0.40 & 0.00 & 0.60 & 0.80 \\
Dfa & 0 & 1 & 6 & 5 & 0.00 & 0.08 & 0.50 & 0.42 & 0.08 & 0.50 \\
Dfb & 13 & 21 & 32 & 41 & 0.12 & 0.20 & 0.30 & 0.38 & 0.32 & 0.42 \\
Dfc & 7 & 10 & 33 & 20 & 0.10 & 0.14 & 0.47 & 0.29 & $\mathbf{0 . 2 4}$ & $\mathbf{0 . 5 7}$ \\
ET & 1 & 2 & 7 & 36 & 0.02 & 0.04 & 0.15 & 0.78 & $\mathbf{0 . 0 7}$ & $\mathbf{0 . 1 7}$ \\
\hline Total & 67 & 202 & 180 & 286 & 0.09 & 0.28 & 0.25 & 0.39 & 0.37 & 0.34 \\
\hline
\end{tabular}

As described in Section 4.3, the potential of a dam to benefit from forecasts is largely dependent on its design specifications, which present comparable values in areas with similar orography and design practices. Forecast skill, on the other hand, is largely dependent on climate teleconnections, which tend to present regional patterns. Further, considering these factors coincidentally is also insightful. Figure 7 illustrates the distribution of the four possible groups of dams across the thirty climate zones of the Köppen-Geiger climate classification system. We notice a few interesting patterns. First, dams with high potential but lacking accurate forecasts (panel (a), red triangles) are often found in humid subtropical climate zones (Cwa, Cfa), particularly in the southeast regions of Australia, China, U.S., and South America. The trend is also true—but not statistically significant—for dams in Southeast Asia (tropical rainforest, $A f$ ) and Pacific Northwest (warm summer Mediterranean, $C s b$ ). Second, dams with good forecasts (panel (a) and (b), blue triangles) are mostly located in the tropical savanna climate zone ( $A w$, Mainland Southeast Asia, India, Brazil, and western Africa) and subartic climate zone ( $D f c$, Canada, Russia, north eastern Europe). While the majority of these dams have poor to fair potential, which can be attributed to relatively large values of time-to-fill, the remaining dams with characteristics conducive for forecast-informed operations can readily benefit from 


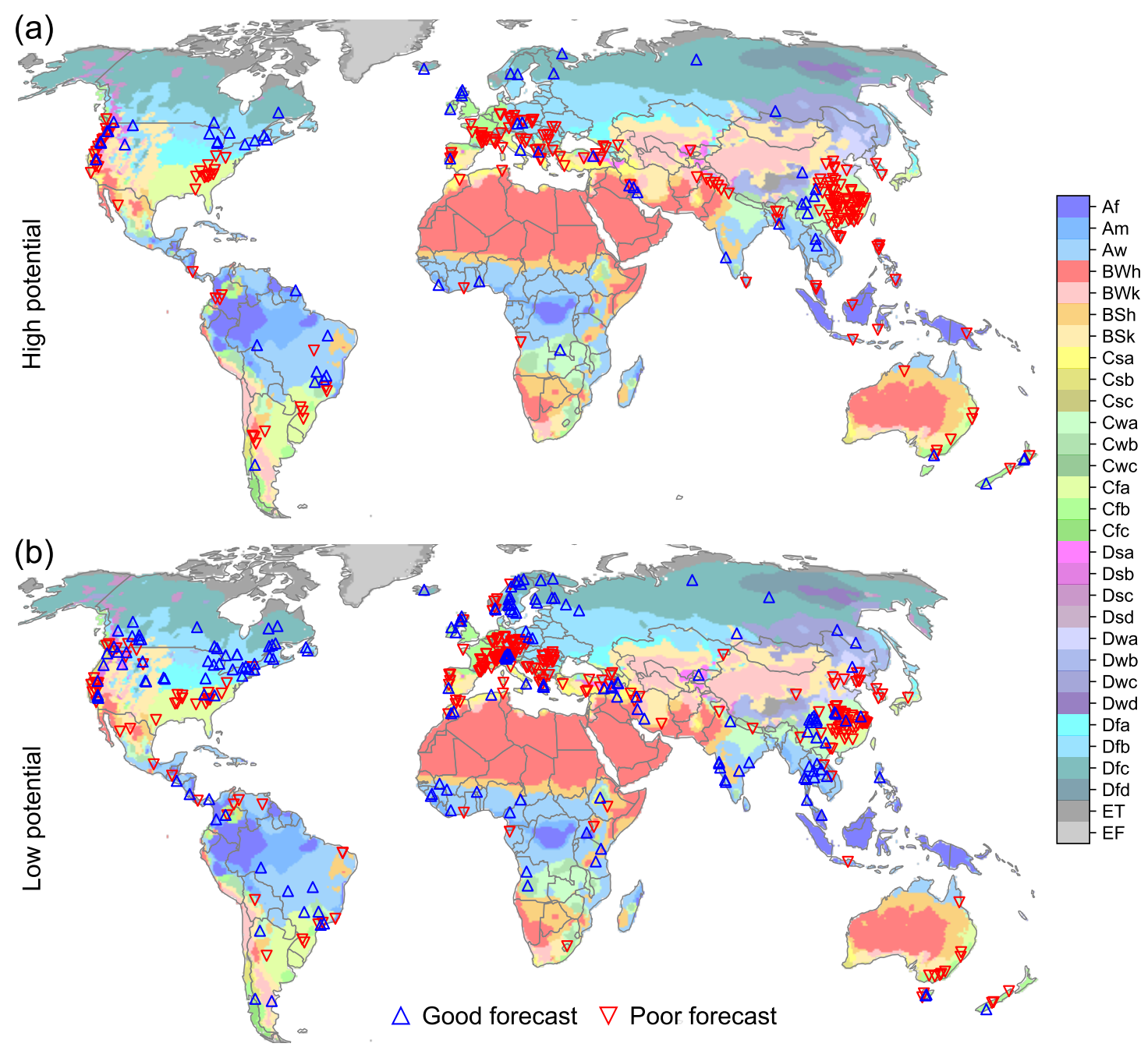

Figure 7. Distribution of dams across climate zones based on their potential to benefit from perfects forecasts. The top (a) and bottom (b) panels represent dams with 'high potential' $\left(I_{P F}>4.7 \%\right)$ and 'low potential' $\left(I_{P F} \leq 4.7 \%\right)$, respectively, while 'good forecast' and 'poor forecast' represent dams with $M d A P E$ less than or greater than $20 \%$, respectively.

including climate signals into their forecast models. This also applies to dams along the U.S.-Canadian border. These dams are located in a humid continental climate zone $(D f b)$, whose statistical significance for high forecast accuracy has been masked by differences in performance between dams located in Europe and North America. Third, dams with low potential and poor forecasts are primarily found in Europe and east Asia (panel (b), red triangles). This trend is significant $(p<0.05)$ for dams in the Alps (alpine climate, $E T$ ), in particular for dams that are characterized by large time-to-fill values and small reservoir depth to maximum hydraulic head ratios. 


\section{Discussion}

\subsection{Implications for planning and management of hydropower projects}

In this study, we examine the relationship between seasonal streamflow forecasts and global hydropower production, accounting for the influence of reservoir characteristics. Specifically, we develop seasonal inflow forecasts for 735 headwater dams based on lagged global and local hydro-climatic variables. The forecasts exhibit fair skill globally, but higher skill in several regions, including the northern extra-tropical regions and the areas characterized by tropical savannah climate (e.g., mainland Southeast Asia, eastern South America, and western Africa). In agreement with earlier work, our forecasts exhibit well-known teleconnections, such as NAO influencing spring-summer peak flow in the northern extra-tropical regions (Lee et al., 2018), ENSO influencing streamflow in Southeast Asia (Sankarasubramanian et al., 2009; Räsänen and Kummu, 2013), and ENSO / PDO influencing winter-spring streamflow in the Pacific Northwest (Hamlet et al., 2002; Voisin et al., 2006).

We then illustrate the relationship between forecast skill, value, and reservoir characteristics by adopting forecasts in the reservoir operations model. While $94 \%$ of dams considered could benefit from perfect forecasts, only $25 \%$ demonstrate improvements when using our realistic forecasts - a fairly low percentage if we consider the forecast skill achieved globally. This highlights the fundamental role of reservoir characteristics in shaping the relationship between forecast skill and value. Key design specifications include time-to-fill, a characteristic identified by other recent studies (Anghileri et al., 2016; Turner et al., 2017a; Yang et al., 2020), hydraulic head, largely dependent on reservoir depth, and the frequency of inflows exceeding maximum turbine release rates, a design specification that allows operators to work with a larger margin of forecast error during high inflow periods. It is worth emphasizing here that these results are not intended to provide site-specific operational guidelines, but do represent a first, qualitative step toward determining the potential benefit of seasonal streamflow forecasts for hydropower operators. The relationships identified here could be used, for example, to understand forecast potential for a given reservoir or to characterize the interplay between climatology, hydrology, and dam characteristics in a large region of interest.

By combining information on reservoir characteristics, forecast skill, and climatic zones, we identify large regions in which dams would benefit the most from forecast application. One such group consists of dams with a strong potential to benefit from forecast-informed operations and that possess good forecast accuracy. In particular, for the tropical savanna and subartic climate, we observe teleconnections that result in higher forecast accuracy. Dams with favorable characteristics in these regions can gain additional benefits from integrating large-scale climate signals within forecast models. Another interesting group consists of dams that may benefit from forecast-informed operations but lack adequate forecast accuracy. Such dams are located in maritime Southeast Asia, the Pacific Northwest, and the humid subtropical climate of the southeast regions of Australia, China, U.S., and South America. These are areas in which watershed-specific analyses may bring immediate benefits to hydropower operators. Such analyses will likely require more nuanced hydro-climatological data than those adopted herefrom observed precipitation in the upstream catchment (Denaro et al., 2017) to temperature and precipitation data forecasted by numerical weather prediction models (Ahmad and Hossain, 2020). 
Finally, it is worth noting that the implications of our study go beyond existing reservoirs: dam planning over large scales may also benefit from these findings. For example, untapped hydropower potential (Zhou et al., 2015; Hoes et al., 2017) and seasonal streamflow predictability could be evaluated to derive some first, qualitative, conclusions on expected reservoir characteristics and performance. A case in point are run-of-the-river dams: these systems have a short time-to-fill characteristic and are therefore suitable for implementing forecast-informed reservoir sizing and operations (Bertoni et al., 2021). Conversely, if new dams are constructed in areas known to lack forecast skill or monitoring systems, then a larger storage capacity may be justifiable for dams operating with basic control rules.

\subsection{Limitations and opportunities}

Like any other global study, the large spatial domain requires building on a number of assumptions that must properly contextualized. First, we assume that the goal of dam operators is to maximize hydropower production over the long term (in addition to providing flood control). While this objective provides a tangible indication of forecast value, it may not be fully representative of the local conditions encountered by operators. For example, operators may be interested to maximize revenue (Anghileri et al., 2018), supply the bulk of power to the grid (Zambon et al., 2012), or complement the generation of other renewable energy sources (Graabak et al., 2019). To account explicitly for these aspects, one needs to model the role that dams play in the power market, as recently done for the Western U.S. (Voisin et al., 2020), England (Byers et al., 2020), or the Greater Mekong (Chowdhury et al., 2020, 2021). With these models, one could also infer the willingness to pay for improved streamflow forecasts based on the economic value derived from their use (Arnal et al., 2016).

Second, release decisions at individual dams may be affected by joint operations between multiple reservoirs and thus better supported with more accurate data and tailored hydrological models surpassing those adopted here. Importantly, these data could include qualitative or quantitative forecasts. Although precipitation and streamflow predictions are not used consistently across the world (Adams and Pagano, 2016), medium- to long-range forecasts are increasingly being adopted by water utilities - as recently shown by Turner et al. (2020) for 300 dams in the conterminous United States. Access to observed and inferred release decisions could thus help researchers provide a more robust and nuanced estimate of forecast value.

Finally, investigation of alternative forecast approaches may be warranted. The adoption of a statistical prediction model is motivated by the availability of relatively long hindcast periods and the desire for long prediction horizons (Section 3.1). However, it is important to note that regional- and global-scale forecasting systems are gaining momentum (Kirtman et al., 2014; Emerton et al., 2018), showing skillful forecasts over large spatial domains and long prediction horizons (Arnal et al., 2018; Towner et al., 2019), and may justify investigation. Importantly, such approaches may not be limited to headwater dams, as long as the underpinning hydrological model (coupled with seasonal forecasts) includes a realistic representation of water management decisions (Pechlivanidis et al., 2020). 
https://doi.org/10.5194/hess-2021-518

Preprint. Discussion started: 30 November 2021

(c) Author(s) 2021. CC BY 4.0 License.

(c) (1)
Hydrology and

Earth System

Sciences

Discussions

\section{Conclusions}

This analysis expands the existing body of knowledge on the relationship between forecast skill, value, and reservoir design for the hydropower sector. As expected, a positive relation between skill and value exists, however we also demonstrate that value is strongly modulated by reservoir characteristics. The two extreme cases are represented by dams that can be profitable with little regard to forecast accuracy and dams that do not appear to benefit from seasonal streamflow forecasts. Considering reservoir characteristics and forecast skill together, we identify regions with high potential to benefit from forecast-informed operations whether forecast accuracy is good or poor. Research that integrates these findings with hydrological-electricity models to quantify economic benefits is warranted. Specifically, this may reflect the willingness to pay for improved forecast models. Such an assessment could provide guidance and insight for large-scale hydropower planning and management, particularly as energy systems become more interconnected.

Code and data availability. The code used to conduct all analyses is available by contacting the authors. All simulations results are available on HydroShare at http://www.hydroshare.org/resource/ca365ffb1a1f49df8b77e393be965fd8.

Author contributions. D.L., J.Y.N., S.G., and P.B. contributed to the conceptualization of this work. The data processing, analyses, and visualization were carried out by D.L. and J.Y.N. The first draft was prepared by D.L., J.Y.N., and S.G. All authors reviewed and edited the final draft.

Competing interests. The authors declare that they have no conflict of interest.

Acknowledgements. Jia Yi Ng and Stefano Galelli are supported by Singapore's Ministry of Education (MoE) through the Tier 2 project 'Linking water availability to hydropower supply—an engineering systems approach' (Award No. MOE2017-T2-1-143). 


\section{References}

Adams, T. E. and Pagano, T. C.: Flood forecasting: A global perspective, Academic Press, 2016.

Ahmad, S. K. and Hossain, F.: A generic data-driven technique for forecasting of reservoir inflow: Application for hydropower maximization, Environmental Modelling \& Software, 119, 147-165, 2019.

Ahmad, S. K. and Hossain, F.: Forecast-informed hydropower optimization at long and short-time scales for a multiple dam network, Journal of Renewable and Sustainable Energy, 12, $014501,2020$.

Alcamo, J., Döll, P., Henrichs, T., Kaspar, F., Lehner, B., Rösch, T., and Siebert, S.: Development and testing of the WaterGAP 2 global model of water use and availability, Hydrological Sciences Journal, 48, 317-337, 2003.

Anghileri, D., Voisin, N., Castelletti, A., Pianosi, F., Nijssen, B., and Lettenmaier, D. P.: Value of long-term streamflow forecasts to reservoir operations for water supply in snow-dominated river catchments, Water Resources Research, 52, 4209-4225, 2016.

Anghileri, D., Castelletti, A., and Burlando, P.: Alpine Hydropower in the Decline of the Nuclear Era: Trade-Off between Revenue and Production in the Swiss Alps, Journal of Water Resources Planning and Management, 144, 04018 037, 2018.

Arnal, L., Ramos, M.-H., Coughlan de Perez, E., Cloke, H. L., Stephens, E., Wetterhall, F., Andel, S. J. v., and Pappenberger, F.: Willingnessto-pay for a probabilistic flood forecast: a risk-based decision-making game, Hydrology and Earth System Sciences, 20, 3109-3128, 2016.

Arnal, L., Cloke, H. L., Stephens, E., Wetterhall, F., Prudhomme, C., Neumann, J., Krzeminski, B., and Pappenberger, F.: Skilful seasonal forecasts of streamflow over Europe?, Hydrology and Earth System Sciences, 22, 2057-2072, 2018.

Bertoni, F., Giuliani, M., Castelletti, A., and Reed, P.: Designing with Information Feedbacks: Forecast Informed Reservoir Sizing and Operation, Water Resources Research, 57, e2020WR028 112, 2021.

505 Bertsekas, D.: Dynamic Programming and Stochastic Control, Academic Press, New York, New York, 1976.

Block, P.: Tailoring seasonal climate forecasts for hydropower operations, Hydrology and Earth System Sciences, 15, 1355-1368, 2011.

Byers, E. A., Coxon, G., Freer, J., and Hall, J. W.: Drought and climate change impacts on cooling water shortages and electricity prices in Great Britain, Nature Communications, 11, 1-12, 2020.

Chowdhury, A. K., Dang, T. D., Bagchi, A., and Galelli, S.: Expected Benefits of Laos' Hydropower Development Curbed by Hydroclimatic Variability and Limited Transmission Capacity: Opportunities to Reform, Journal of Water Resources Planning and Management, 146, $05020019,2020$.

Chowdhury, K. A., Dang, T. D., Nguyen, H. T., Koh, R., and Galelli, S.: The Greater Mekong's climate-water-energy nexus: how ENSOtriggered regional droughts affect power supply and $\mathrm{CO}_{2}$ emissions, Earth's Future, 9, e2020EF001 814, 2021.

Crochemore, L., Ramos, M.-H., and Pechlivanidis, I.: Can continental models convey useful seasonal hydrologic information at the catchment scale?, Water Resources Research, 56, e2019WR025 700, 2020.

De Felice, M., Dubus, L., Suckling, E., and Troccoli, A.: The impact of the North Atlantic Oscillation on European hydro-power generation, https://doi.org/10.31223/osf.io/8sntx, 2018.

Denaro, S., Anghileri, D., Giuliani, M., and Castelletti, A.: Informing the operations of water reservoirs over multiple temporal scales by direct use of hydro-meteorological data, Advances in Water Resources, 103, 51-63, 2017.

Döll, P. and Lehner, B.: Validation of a new global 30-min drainage direction map, Journal of Hydrology, 258, 214-231, 2002.

Döll, P., Fiedler, K., and Zhang, J.: Global-scale analysis of river flow alterations due to water withdrawals and reservoirs, Hydrology and Earth System Sciences, 13, 2413-2432, 2009. 
https://doi.org/10.5194/hess-2021-518

Preprint. Discussion started: 30 November 2021

(C) Author(s) 2021. CC BY 4.0 License.
Hydrology and

Earth System

Sciences

Discussions

Emerton, R., Zsoter, E., Arnal, L., Cloke, H. L., Muraro, D., Prudhomme, C., Stephens, E. M., Salamon, P., and Pappenberger, F.: Developing a global operational seasonal hydro-meteorological forecasting system: GloFAS-Seasonal v1. 0, Geoscientific Model Development, 11, 3327-3346, 2018.

Enfield, D. B., Mestas-Nuñez, A. M., and Trimble, P. J.: The Atlantic Multidecadal Oscillation and its relation to rainfall and river flows in the continental US, Geophysical Research Letters, 28, 2077-2080, https://doi.org/10.1029/2000GL012745, 2001.

Gelati, E., Madsen, H., and Rosbjerg, D.: Reservoir operation using El Niño forecasts—case study of Daule Peripa and Baba, Ecuador, Hydrological Sciences Journal, 59, 1559-1581, 2014.

GEO: Global Energy Observatory: Information on Global Energy Systems and Infrastructure, available online at http://globalenergyobservatory.org, 2016.

Giuliani, M., Zaniolo, M., Castelletti, A., Davoli, G., and Block, P.: Detecting the state of the climate system via artificial intelligence to improve seasonal forecasts and inform reservoir operations, Water Resources Research, 55, 9133-9147, 2019.

Graabak, I., Korpås, M., Jaehnert, S., and Belsnes, M.: Balancing future variable wind and solar power production in Central-West Europe with Norwegian hydropower, Energy, 168, 870-882, 2019.

Grill, G., Lehner, B., Thieme, M., Geenen, B., Tickner, D., Antonelli, F., Babu, S., Borrelli, P., Cheng, L., Crochetiere, H., et al.: Mapping the world's free-flowing rivers, Nature, 569, 215, http://www.nature.com/articles/s41586-019-1111-9, 2019.

Gupta, H. V., Kling, H., Yilmaz, K. K., and Martinez, G. F.: Decomposition of the mean squared error and NSE performance criteria: Implications for improving hydrological modelling, Journal of hydrology, 377, 80-91, 2009.

540 Haddeland, I., Heinke, J., Biemans, H., Eisner, S., Flörke, M., Hanasaki, N., Konzmann, M., Ludwig, F., Masaki, Y., Schewe, J., et al.: Global water resources affected by human interventions and climate change, Proceedings of the National Academy of Sciences, 111, 3251-3256, 2014.

Hamlet, A. F., Huppert, D., and Lettenmaier, D. P.: Economic value of long-lead streamflow forecasts for Columbia River hydropower, Journal of Water Resources Planning and Management, 128, 91-101, 2002.

545 Harrigan, S., Zoster, E., Cloke, H., Salamon, P., and Prudhomme, C.: Daily ensemble river discharge reforecasts and real-time forecasts from the operational Global Flood Awareness System, Hydrology and Earth System Sciences Discussions, pp. 1-22, 2020.

Hejazi, M. I., Cai, X., and Ruddell, B. L.: The role of hydrologic information in reservoir operation-learning from historical releases, Advances in Water Resources, 31, 1636-1650, 2008.

Hoes, O. A., Meijer, L. J., Van Der Ent, R. J., and Van De Giesen, N. C.: Systematic high-resolution assessment of global hydropower potential, PloS one, 12, e0171 844, 2017.

Hurrell, J. W. and Deser, C.: North Atlantic climate variability: the role of the North Atlantic Oscillation, Journal of Marine Systems, 79, 231-244, https://doi.org/10.1016/j.jmarsys.2009.11.002, 2010.

ICOLD: World Register of Dams. Version Updates 1998-2009, Tech. rep., International Commission on Large Dams, Paris, France, available online at www.icold-cigb.net, 2011.

555 IHA: 2019 Hydropower Status Report, Tech. rep., https://www.hydropower.org/status2019, 2019.

Johnson, S. J., Stockdale, T. N., Ferranti, L., Balmaseda, M. A., Molteni, F., Magnusson, L., Tietsche, S., Decremer, D., Weisheimer, A., Balsamo, G., et al.: SEAS5: the new ECMWF seasonal forecast system, Geoscientific Model Development, 12, 1087-1117, 2019.

Jolliffe, I.: Principal Component Analysis, Springer-Verlag New York, Cambridge MA, https://doi.org/10.1007/b98835, 2002.

Kaveh, K., Hosseinjanzadeh, H., and Hosseini, K.: A new equation for calculation of reservoir's area-capacity curves, KSCE Journal of Civil

Engineering, 17, 1149-1156, 2013. 
Kim, Y.-O. and Palmer, R. N.: Value of seasonal flow forecasts in Bayesian stochastic programming, Journal of Water Resources Planning and Management, 123, 327-335, 1997.

Kirtman, B. P., Min, D., Infanti, J. M., Kinter, J. L., Paolino, D. A., Zhang, Q., Van Den Dool, H., Saha, S., Mendez, M. P., Becker, E., et al.: The North American multimodel ensemble: phase-1 seasonal-to-interannual prediction; phase-2 toward developing intraseasonal prediction, Bulletin of the American Meteorological Society, 95, 585-601, 2014.

Lee, D., Ward, P., and Block, P.: Attribution of Large-Scale Climate Patterns to Seasonal Peak-Flow and Prospects for Prediction Globally, Water Resources Research, 54, 916-938, https://doi.org/10.1002/2017WR021205, 2018.

Lehner, B. and Döll, P.: Development and validation of a global database of lakes, reservoirs and wetlands, Journal of Hydrology, 296, 1-22, 2004.

Lehner, B., Verdin, K., and Jarvis, A.: New global hydrography derived from spaceborne elevation data, Eos, Transactions American Geophysical Union, 89, 93-94, 2008.

Lehner, B., Liermann, C. R., Revenga, C., Vörösmarty, C., Fekete, B., Crouzet, P., Döll, P., Endejan, M., Frenken, K., Magome, J., et al.: Highresolution mapping of the world's reservoirs and dams for sustainable river-flow management, Frontiers in Ecology and the Environment, 9, 494-502, 2011.

Libisch-Lehner, C., Nguyen, H., Taormina, R., Nachtnebel, H., and Galelli, S.: On the Value of ENSO State for Urban Water Supply System Operators: Opportunities, Trade-Offs, and Challenges, Water Resources Research, 55, 2856-2875, 2019.

Liebe, J., Van De Giesen, N., and Andreini, M.: Estimation of small reservoir storage capacities in a semi-arid environment: A case study in the Upper East Region of Ghana, Physics and Chemistry of the Earth, Parts A/B/C, 30, 448-454, 2005.

Loucks, D. P., Van Beek, E., Stedinger, J. R., Dijkman, J. P., and Villars, M. T.: Water resources systems planning and management: an introduction to methods, models and applications, Paris: UNESCO, 2005.

Maurer, E. P. and Lettenmaier, D. P.: Potential effects of long-lead hydrologic predictability on Missouri River main-stem reservoirs, Journal of Climate, 17, 174-186, 2004.

McHugh, M. L.: Interrater reliability: the kappa statistic, Biochemia medica: Biochemia medica, 22, 276-282, 2012.

Ng, J. Y., Turner, S. W., and Galelli, S.: Influence of El Niño Southern Oscillation on global hydropower production, Environmental Research Letters, 12, 034 010, 2017.

Nowak, K., Prairie, J., Rajagopalan, B., and Lall, U.: A nonparametric stochastic approach for multisite disaggregation of annual to daily streamflow, Water Resources Research, 46, 2010.

Pastor, A., Ludwig, F., Biemans, H., Hoff, H., and Kabat, P.: Accounting for environmental flow requirements in global water assessments, Hydrology and Earth System Sciences, 18, 5041-5059, 2014.

Pechlivanidis, I., Crochemore, L., Rosberg, J., and Bosshard, T.: What are the key drivers controlling the quality of seasonal streamflow forecasts?, Water Resources Research, 56, e2019WR026 987, 2020.

Peel, M. C., Finlayson, B. L., and McMahon, T. A.: Updated world map of the Köppen-Geiger climate classification, Hydrology and Earth System Sciences, 11, 2007.

Räsänen, T. A. and Kummu, M.: Spatiotemporal influences of ENSO on precipitation and flood pulse in the Mekong River Basin, Journal of Hydrology, 476, 154-168, 2013.

Rheinheimer, D. E., Bales, R. C., Oroza, C. A., Lund, J. R., and Viers, J. H.: Valuing year-to-go hydrologic forecast improvements for a peaking hydropower system in the Sierra Nevada, Water Resources Research, 52, 3815-3828, 2016. 
Sankarasubramanian, A., Lall, U., Devineni, N., and Espinueva, S.: The role of monthly updated climate forecasts in improving intraseasonal water allocation, Journal of Applied Meteorology and Climatology, 48, 1464-1482, 2009.

Soncini-Sessa, R., Weber, E., and Castelletti, A.: Integrated and participatory water resources management-Theory, vol. 1, Elsevier, Amsterdam, NL, 2007.

Towner, J., Cloke, H. L., Zsoter, E., Flamig, Z., Hoch, J. M., Bazo, J., Coughlan de Perez, E., and Stephens, E. M.: Assessing the performance of global hydrological models for capturing peak river flows in the Amazon basin, Hydrology and Earth System Sciences, 23, 3057-3080, 2019.

Troin, M., Arsenault, R., Wood, A. W., Brissette, F., and Martel, J.-L.: Generating ensemble streamflow forecasts: A review of methods and approaches over the past 40 years, Water Resources Research, p. e2020WR028392, 2021.

Turner, S. W. and Galelli, S.: Water supply sensitivity to climate change: an R package for implementing reservoir storage analysis in global and regional impact studies, Environmental Modelling \& Software, 76, 13-19, 2016.

Turner, S. W., Bennett, J. C., Robertson, D. E., and Galelli, S.: Complex relationship between seasonal streamflow forecast skill and value in reservoir operations, Hydrology and Earth System Sciences, 21, 4841-4859, 2017a.

Turner, S. W., Ng, J. Y., and Galelli, S.: Examining global electricity supply vulnerability to climate change using a high-fidelity hydropower dam model, Science of the Total Environment, 590, 663-675, 2017b.

Turner, S. W., Xu, W., and Voisin, N.: Inferred inflow forecast horizons guiding reservoir release decisions across the United States, Hydrology and Earth System Sciences, 24, 1275-1291, 2020.

Van Beek, L., Wada, Y., and Bierkens, M. F.: Global monthly water stress: 1. Water balance and water availability, Water Resources Research, 47, 2011.

Van Vliet, M. T., Wiberg, D., Leduc, S., and Riahi, K.: Power-generation system vulnerability and adaptation to changes in climate and water resources, Nature Climate Change, 6, 375, 2016.

Voisin, N., Hamlet, A. F., Graham, L. P., Pierce, D. W., Barnett, T. P., and Lettenmaier, D. P.: The role of climate forecasts in Western US power planning, Journal of Applied Meteorology and Climatology, 45, 653-673, 2006.

Voisin, N., Dyreson, A., Fu, T., O'Connell, M., Turner, S. W., Zhou, T., and Macknick, J.: Impact of climate change on water availability and its propagation through the Western US power grid, Applied Energy, 276, 115 467, 2020.

Ward, P. J., Eisner, S., Flörke, M., Dettinger, M. D., and Kummu, M.: Annual flood sensitivities to El Niño-Southern Oscillation at the global scale, Hydrology and Earth System Sciences, 18, 47-66, 2014.

Weedon, G., Gomes, S., Viterbo, P., Shuttleworth, W. J., Blyth, E., Österle, H., Adam, J., Bellouin, N., Boucher, O., and Best, M.: Creation of the WATCH forcing data and its use to assess global and regional reference crop evaporation over land during the twentieth century, Journal of Hydrometeorology, 12, 823-848, 2011.

Wilks, D. S.: Statistical methods in the atmospheric sciences, vol. 100, Academic press, 2011.

Yamazaki, D., Ikeshima, D., Sosa, J., Bates, P. D., Allen, G. H., and Pavelsky, T. M.: MERIT Hydro: A high-resolution global hydrography map based on latest topography dataset, Water Resources Research, 55, 5053-5073, 2019.

Yang, G., Guo, S., Liu, P., and Block, P.: Integration and Evaluation of Forecast-Informed Multiobjective Reservoir Operations, Journal of Water Resources Planning and Management, 146, 04020 038, 2020.

Yang, G., Guo, S., Liu, P., and Block, P.: Sensitivity of Forecast Value in Multiobjective Reservoir Operation to Forecast Lead Time and Reservoir Characteristics, Journal of Water Resources Planning and Management, 147, 04021 027, 2021. 
https://doi.org/10.5194/hess-2021-518

Preprint. Discussion started: 30 November 2021

(c) Author(s) 2021. CC BY 4.0 License.

(c) (1)
Hydrology and Earth System Sciences

Discussions

635 You, J.-Y. and Cai, X.: Determining forecast and decision horizons for reservoir operations under hedging policies, Water Resources Research, 44, 2008.

Zambon, R. C., Barros, M. T. L., Lopes, J. E. G., Barbosa, P. S. F., Francato, A. L., and Yeh, W. W.-G.: Optimization of Large-Scale Hydrothermal System Operation, Journal of Water Resources Planning and Management, 138, 135-143, 2012.

Zarfl, C., Lumsdon, A. E., Berlekamp, J., Tydecks, L., and Tockner, K.: A global boom in hydropower dam construction, Aquatic Sciences, 640 $77,161-170,2015$.

Zeng, R., Cai, X., Ringler, C., and Zhu, T.: Hydropower versus irrigation—an analysis of global patterns, Environmental Research Letters, 12, $034006,2017$.

Zhang, X., Li, H.-Y., Deng, Z. D., Ringler, C., Gao, Y., Hejazi, M. I., and Leung, L. R.: Impacts of climate change, policy and Water-EnergyFood nexus on hydropower development, Renewable energy, 116, 827-834, 2018.

645 Zhang, Y., Wallace, J. M., and Battisti, D. S.: ENSO-like interdecadal variability: 1900-93, Journal of climate, 10, 1004-1020, https://doi. org/10.1175/1520-0442(1997)010<1004:ELIV>2.0.CO;2, 1997.

Zhao, T., Yang, D., Cai, X., Zhao, J., and Wang, H.: Identifying effective forecast horizon for real-time reservoir operation under a limited inflow forecast, Water Resources Research, 48, 2012.

Zhou, Y., Hejazi, M., Smith, S., Edmonds, J., Li, H., Clarke, L., Calvin, K., and Thomson, A.: A comprehensive view of global potential for hydro-generated electricity, Energy \& Environmental Science, 8, 2622-2633, 2015. 